\title{
IMAGINÁRIO E REPRESENTAÇÕES MÍTICAS: AS BELAS PALAVRAS (AYVU PORÃ) DOS CANTOS DIVINOS (MBORAI) GUARANI MBYA
}

\author{
ALZIRA LOBO ARRUDA CAMPOS ${ }^{1}$ \\ UNISA \\ MARÍLIA GOMES CHIZZI GODOY ${ }^{2}$ \\ UNISA
}

RAIMUNDA MARIA RODRIGUES SANTOS ${ }^{3}$

IFRR

\begin{abstract}
RESUMO: Os discursos poéticos dos mborai (cantos) Guarani Mbya, registrados em CDs lançados por grupos de canto e dança, são representativos do imaginário cultural desse povo, comprometido com sua concepção mitológica. Os conteúdos sagrados desses cantos estão ligados às divindades e permitem entender a dimensão espaço-temporal da cultura Guarani Mbya. Neles, as experiências históricas são retratadas como reais, e o mito origina-se enquanto expressão fundacional da vida e dos homens. As narrativas míticas dos cantos, concebidas como as "belas palavras" (ayvu porã), são parte integrante do "belo saber" (arandu porã) $e$ encaminham essa discussão, que tem por foco a significação das identidades míticas divinas registradas nas letras desses cantos.
\end{abstract}

PALAVRAS-CHAVE: canto (mborai) Guarani Mbya; cosmologia; discurso mítico; grupo de canto-dança (mborai-jeroky); teogonia.

ABSTRACT: The poetic discourses of the Guarani Mbya mborai (chants), which were recorded in CDs released by chants and dance groups, are representatives of this people's cultural imagery, compromised to its mythological conception. Through the sacred contents of the chants, always linked to praised deities, we can understand the space-time dimension of the Guarani Mbya culture, in which the historical experiences are portrayed as real, and the myth arises as a

\footnotetext{
${ }^{1}$ Livre-docente em Metodologia da História pela Universidade Estadual de São Paulo (UNESP); Doutora e Mestra em História Social pela Universidade de São Paulo (USP); docente do Mestrado Interdisciplinar em Ciências Humanas da Universidade de Santo Amaro (UNISA). Email: loboarruda@hotmail.com .

${ }^{2}$ Doutora em Psicologia Social pela Pontifícia Universidade Católica (PUC-SP); Mestra em Antropologia Social pela Universidade de São Paulo (USP); docente do Mestrado Interdisciplinar em Ciências Humanas da Universidade de Santo Amaro (UNISA). Email: mgggodoy@yahoo.com.br .

${ }^{3}$ Doutoranda no Programa de Ciências Sociais da Universidade do Vale do Rio dos Sinos (UNISINOS); Mestra em Educação, Administração e Comunicação pela Universidade São Marcos (UNIMARCOS-SP); Professora do Instituto Federal de Educação, Ciência e Tecnologia de Roraima (IFRR). E-mail: raimundarodrigues@ifrr.edu.br.
} 
foundational expression of life and mankind. The mythical narratives of the chants, conceived as ayvu porã ("the beautiful words"), are seen as an intrinsic part of the "beautiful knowledge" (arandu porã) and lead to this discussion, which focuses on debating the signification of those divine mythical identities registered in the words of the chants.

KEYWORDS: Guarani Mbya chant (mborai); cosmology; mythical discourse; chant-and-dance group (mborai-jeroky); theogony.

\section{Introdução}

A música e o sagrado - sejam as festas, os cultos, as adorações, as preces ou os cantos rituais - têm sido avaliados como expressões centrais dos universos simbólicos indígenas, historicamente registrados por meio de formas sonoras, que permitem um contato religioso com divindades diversas (TERRIN, 2004). Entre os domínios do som e de seus sentidos míticos, destaca-se o cenário cultural do povo Guarani, que ocupa áreas do Sudeste, Sul e Centro-oeste do Brasil, além de regiões da Argentina, do Paraguai e do Uruguai. Dentre os seus três subgrupos em território brasileiro, os Kaiova, os Nhandeva/Xiripa e os Mbya (família linguística Tupi-Guarani, tronco Tupi), são os últimos o foco deste estudo. As manifestações culturais destes foram influenciadas pelas práticas missioneiras no Brasil colonial, dentre as quais destaca-se a música enquanto eixo central da sociabilidade indígena (MONTARDO, 2002; STEIN, 2009; CASTAGNA, 1997).

O presente artigo reflete sobre a religiosidade e as visões de mundo expressas em cânticos do subgrupo Mbya, que se distingue dos demais por ter conseguido se manter isolado e arredio ao contato com os colonizadores por mais de um século após o descobrimento. Como viviam no interior das matas da América do Sul, os Guarani Mbya eram chamados de ka'aygua, "os que habitavam as florestas" (GODOY, 2003; LITAIFF, 2004, p. 18).

A população geral dos Guarani em 2010, segundo o Conselho Indigenista Missionário, era de aproximadamente 225 mil pessoas ${ }^{4}$, das

\footnotetext{
${ }^{4} \mathrm{O}$ ensino musical sempre foi intenso durante a permanência dos jesuítas no Brasil, desempenhando forte papel no ministério com os indígenas. Da insistência nessa arte surgiriam índios capazes de reproduzir todas as manifestações musicais básicas do culto cristão: os nheengaribas, ou "músicos da terra", como seriam
} 
quais 67.523 habitam áreas no Sul, Centro-oeste e Sudeste do Brasil (IBGE, 2010). No Estado de São Paulo, os Mbya compreendem 4.557 pessoas (IBGE, 2010), população essa distribuída em 19 aldeias.

A música e a dança ocupam um lugar central na cosmologia Guarani, pois traduzem o caminhar real, esforçado, livre, sem alienação e sem opressão, baseado no encontro entre a boa terra Guarani e a dimensão de uma "terra sem males" ( $Y v y$ Mara Ẽ̂̃). Essas manifestações se impõem na cultura com uma discursividade própria, como expressão de sua totalidade (MELIÀ, 1989). Tal fenômeno inscreve-se na proposta de participação e compartilhamento que grupos Guaranis de canto-dança (mborai-jeroky) vêm projetando na sociedade, na tentativa de constituírem não só um cenário coeso de espetáculo e representação da cultura, mas também um recorte da realidade, situado no entrecruzamento do tempo vivido (ete: "real"; aỹ: "agora") com o tempo sagrado (yma: "antigo").

Os mborai, objeto da investigação aqui apresentada, poderiam desdobrar-se em diferentes temas, tais como: a "terra sem males", os rituais e os objetos sagrados, a preparação de guerreiros e guerreiras (xondaro, xondaria), os animais de estimação de Nhanderu (mymba'i) e as coisas ( $m b a$ 'emo) da natureza, como frutos, árvores e animais. (GODOY e SILVA, 2014, p. 22). Contudo, o olhar deste artigo recai sobre as narrativas míticas dos cantos, concebidas como as "belas palavras" (ayvu porâ), as quais compreendem o "belo saber" (arandu porã) e fornecem a base para esta discussão a respeito do significado, para os Mbya, das identidades míticas divinas, registrados nas letras dos cantos (mboral).

Entende-se que o mito se produz como um discurso fundador e se recria poeticamente, ritualizando-se e expressando-se de forma histórica e material (BORGES, 1998, 2001 e 2002; HUIZINGA, 1971). Segundo essa vertente, a mitopoesia emerge "como uma unidade cultural, poética e discursiva bastante complexa, na qual se intercruzam elementos do fantasiamento, da personificação simbólica de noções morais e sociais, de racionalização sobre a origem e a existência do mundo e do homem" (BORGES, 1998, p. 174).

conhecidos entre os portugueses. Nas missões do Sul, no século XVIII, eles alcançaram um estágio extraordinário de desenvolvimento, construindo seus próprios instrumentos e executando música europeia de relativa complexidade técnica (CASTAGNA, 1997). 
Perfilhadas essas análises e diante da complexidade desse fenômeno, as experiências aqui retratadas provêm do convívio direto e indireto das pesquisadoras com os Mbya das aldeias de São Paulo Tenonde Porã, Krukutu, Tekoa Pyau, Tekoa Ytu, Rio Silveira e Boa Vista (estas últimas do litoral paulista) nos últimos decênios. Vivência essa que nos permite afirmar, conforme será demonstrado no corpo deste trabalho, que os cantos (mboral) são mitopoemas que reproduzem o imaginário social indígena, expresso como discurso oral. Eles refletem a tradição ao constituir, por si próprios, um material-memória e um inventário cultural. A inspiração divina exprime a autoria imemorável com que se traduz a palavra rezada (poraei, mborael). Ouve-se com muita frequência o termo arandu porã, a designar a "sabedoria sagrada", como uma expressão própria dos mborai.

\section{Cosmologia Guarani Mbya: fundamentos das "belas palavras" (ayvu porã)}

As produções etnológicas Guarani Mbya reiteram a existência de uma cosmologia que considera o universo um ideal de busca contínua, compreendendo-o como a moradia dos deuses, como um lugar de imagem verdadeira, de conhecimento e de beleza primordial, sendo o cosmo denominado Yvy Mara Ě̃y ("terra sem males"). Essa concepção constitui o pano de fundo do qual se origina um tipo de profetismo que se impõe como linguagem divina na ordem discursiva religiosa. Trata-se de um contexto cultural que legitima a importância dos messias enquanto figuras representativas do grupo étnico e defensores de um ideal comum, cujo objetivo é reforçar o sentimento comunitário e fazê-lo progredir continuamente (SCHADEN, 1969, p. 248). As condições proféticas aludem a um movimento expansivo e progressivo em torno desse ideal e de sua dinâmica evolutiva, e a criatividade se expressa no seu próprio curso evolutivo (CLASTRES, 1990). Essa realidade se configura pelo termo oguero-jera, que compreende o exercício de abrir, de criar no curso de sua própria evolução, de desdobrar-se em seu próprio desdobramento (CADOGAN, 1959, p. 17).

A etnologia registra essa dimensão teológica com relação à condição subjetiva em que a vida se expressa na terra. A prevalência 
cosmológica e social implica uma concepção do sujeito divino que, neste contexto histórico, subentende uma dinâmica profética através da qual os indivíduos se tornam responsáveis por um devir sonhado e pela busca incessante do além (SCHADEN, 1974). Isso implica reconhecer que, para os Guarani, a condição humana, em sua incompletude, corresponde à constituição histórica da era da imperfeição, designada como teko axy ("modo de ser imperfeito"). Longe de ser uma forma abstrata de estar no mundo, esse modo de ser indica a necessidade de uma memorização, de um compromisso - e os poderes expressivos das figuras divinas encaminham, hierárquica e progressivamente, esse misticismo Guarani. Os deuses destacam-se por uma sabedoria própria, e não por um modelo de pessoa justa e boa (SCHADEN, 1969, p. 123).

A dinâmica descrita toca em um ponto crítico da cultura ao incluir um Ser Supremo no panteão Guarani. A esse respeito observa-se que, no conjunto dos seres superiores, distingue-se uma entidade de existência eterna, de natureza profundamente ética: um ser onisciente, beneficente e onipotente, criador do universo e da humanidade, autor dos preceitos morais, que recompensa os bons, castiga os maus e que, acima de tudo, mantém uma relação vital com os negócios humanos, sendo, por isso, objeto de preces, sacrifícios e cerimônias formais (SCHADEN, 1969, p. 107-108). Na teogonia Mbya, destacam-se quatro divindades: Nhamandu e sua esposa Jaxuka, deuses do sol; Tupã Ru Ete e sua esposa Para, deuses da água, do trovão e dos raios; Karai Ru Ete e sua esposa Kerexu, deuses do fogo e donos do ruído e do crepitar das chamas; e, por fim, Jakaira e sua esposa Ysapy, deuses da neblina, designados como deuses da primavera (CADOGAN, 1959; LITAIFF, 2004).

Cabe destacar que a palavra divina revela a primazia do universo cosmológico sobre o social, do qual é princípio e destino final. Por isso, escutar e entender as palavras divinas são os meios de realização do ser, de construção da história. Como ensina Melià (1989, p. 306), para os Guarani, "a palavra é tudo e tudo é palavra". Essa afirmação confirma-se nas expressões $n h e$ 'e e $a y v u$, que indicam a palavra, a fala e a língua como porções divinas da alma: alma-palavra e palavra-alma. Nhe'e é o espírito que os deuses enviam para que se encarne nas criaturas prestes a nascer (CADOGAN, 1959). Para completar esse quadro, deve-se observar que ery é o nome através do qual se origina a alma, que se constrói na vida como 
fluxo da realidade do ser (MELIÀ, 1989). Entende-se, dessa forma, que, para os Guarani, toda vida compromete-se miticamente por meio das experiências da palavra e do dizer enquanto atos de representação, levando-se em conta que a alma "no es una parte del ser, sino la vida misma como un todo" (CHAMORRO, 1998, p. 49).

A importância da palavra ganha ênfase ritual própria nas cerimônias mborai-jeroky (canto-dança), momento em que os participantes dirigem as suas ações e entram em contato com os seus deuses. Nesses rituais, destacam-se as produções musicais, categorias conceituais do universo e dimensões sonoras da vida Mbya (STEIN, 2009), que configuram uma produção poética expressiva na qualidade de mitopoemas. Os criadores das letras afirmam que se trata de uma ação mboypy ("fazer-se mito"), conceituação corroborada pela Antropologia: "Para os Guarani, linguagem poética é linguagem dos deuses, dos pássaros, das árvores, da cachoeira, da terra, do sol. Linguagem poética e musical. Ñe'e porã, as famosas belas palavras, então, são poesia e música" (MONTARDO, 2002, p. 153).

Seguindo nessa perspectiva, apresenta-se, na sequência, uma leitura de cantos Guarani, visando a discutir a significação das identidades míticas divinas para esse povo. Antes, porém, é relevante expor a trajetória do movimento cultural nas comunidades Guarani Mbya que resultou na coletânea de cantos de onde foram retirados os textos para análise.

\section{Mborai-jeroky (grupos de canto-dança): CDs e atuação intercultural}

A criação de CDs em aldeias Guarani Mbya decorreu de um movimento designado Memória Viva Guarani, iniciado na comunidade Tenondé Porã em 1998. Os CDs Nande Reko Arandu (1998) e Nande Arandu Pygua (2005) foram as primeiras produções desse movimento e contaram com a participação de jovens e crianças a partir dos 7-8 anos das aldeias Tenondé Porã, Krukutu e Boa Vista, de São Paulo, e Bracuí, do Rio de Janeiro ${ }^{5}$. Dessa forma, instituiu-se um novo lugar de significação nas condições sócio-históricas desse povo, comprometendo o processo

\footnotetext{
${ }^{5}$ Disponível em http://cpisp.org.br/indios/html/saiba-mais/24/o-povo-indigena-guarani.aspx, acessado em $16 / 10 / 2015$.
} 
de investimento sagrado tradicional com as novas tecnologias de som e imagem. Esse movimento divulga a cosmologia Guarani através de sinais sonoro-musicais diacríticos de sua cultura, reafirmando a centralidade da música na vida da comunidade - ou a sua "cosmo-sônica" (STEIN, 2009, p. 102).

Os xondaro 6 ruxiva (líderes indígenas dos grupos de dança) e outros líderes religiosos afirmam que os CDs e as demais apresentações culturais têm por objetivo permitir que os indígenas possam "mostrar sua cultura, quem eles são, para os não-índios". No encarte do CD1, Nhande Reko Arandu, lê-se:

Através da gravação dos cânticos, a gente vai estar apresentando, também, quinhentos anos de resistência à dominação dos povos brancos. Através da gravação, a gente vai estar em forma de protesto (Nhande Reko Arandu, p. 2).

Os repertórios musicais dos quatro CDs aqui analisados foram escolhidos tendo em vista a nossa proposta de construção do foco temático a partir dos deuses, adotando-se o critério de divulgação e domínio dos mborai, na área pesquisada. Essa análise se concentrou nas divindades Nhamandu, Tupã e Tupã Ra'y. Portanto, para efeitos analíticos, compõem o presente estudo textos retirados das seguintes fontes: o CD1, Nande Reko Arandu (traduzido por "Memória Viva Guarani"), de 1998; o CD2, Ñande Arandu Pygua ("Nossa sabedoria"), de 2004; o CD3, Tape Mirim ("Caminho Sagrado"), não datado; e, por fim, o CD4, Kyringue Nhembovy'a ("Guardiões Guarani”), de 20097.

\section{Nhamandu oua re ("Nhamandu surge no céu")}

\footnotetext{
${ }^{6}$ Esse projeto foi resultado de uma iniciativa do sociólogo Maurício Fonseca e contou com o apoio da Secretaria Estadual de Cultura, do Conselho Estadual dos Povos Indígenas e do Instituto Teko Arandu Memória Viva Guarani. A produção dos CDs obteve patrocínio de vários órgãos e entidades (Caritas brasileira, Centro de Estudos e Pesquisas de Administração Municipal, Fundo Social de Solidariedade do Estado de São Paulo, Secretaria do Estado da Educação), conforme consta no encarte do CD Nhande Arandu Pygua.

7 O termo xondaro é traduzido por "soldado" (R. A. DOOLEY, Vocabulário do Guarani, p. 197) e compreende uma iniciativa cultural ligada à educação tradicional dos jovens, na qual se inserem um repertório de dança e a execução de músicas de temática ligada a desempenhos e protagonismos de luta, enfrentamento, ataque.
} 
Das 15 faixas do CD1, observam-se os mborai dirigidos a Nhamandu, transcritos e traduzidos nos quadros abaixo:

\begin{tabular}{|l|l|}
\hline NHAMANDU (faixa 6) & Nhamandu \\
\hline & \\
NHAMANDU JOGWERU & Nhamandu (sol) nasce \\
NHANDERU TENONDE OMA'E & com seus raios e sua sabedoria \\
NHANDEXY TENONDE & Nosso Pai Supremo olha para nós \\
NHANDERE OMA' $\tilde{E}$ & Nossa Mãe Suprema olha para nós \\
\hline
\end{tabular}

\begin{tabular}{|c|c|}
\hline NHAMANDU MIRI (faixa 12) & Pequeno Sol \\
\hline NHAMANDU MIRĨ OGUÊROA PU'Ã & Pequeno Sol \\
\hline OJEXAKA OGUERRO GUATA & Levando sua luz \\
\hline OGUÊRO GUATA & E caminhando \\
\hline 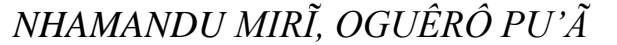 & Com sua sabedoria \\
\hline OJEXAKA, OGUERO GUATA & E com seu raio eterno \\
\hline OGUERO GUATA & \\
\hline NHAMANDU MIRĨ OGUÊRÔ PU' $\tilde{A}$ & \\
\hline OJEXАKА & \\
\hline OGUERO GUATA & \\
\hline NHAMANDU MIRĨ OGUÊRÔ PU' $\tilde{A}$ & \\
\hline OJEXАKA & \\
\hline OGUERO GUATA OGUERO GUATA & \\
\hline
\end{tabular}

No duplo CD2, Nande Arandu Pygua ("Nossa Sabedoria"), constam 27 faixas; destas, quatro se dirigem a Nhamandu. Duas estão transcritas abaixo:

\begin{tabular}{|l|l|}
\hline NHAMANDU JEXAKAA (faixa 18) & O clarão de Nhamandu \\
\hline NHAMANDU JEXAKAA RUPI MEME & O clarão de Nhamandu \\
OPA RUPI & Ilumina em todo lugar \\
NHOGUEROPU'Ã & Ele se levanta do outro lado \\
VA'E ROVAI & Nos faz levantar \\
NHANHOGUEROPU'Ã & Nos erguemos com Ele e sorrimos \\
NHANDERORY'I & Nos erguemos com Ele e sorrimos \\
NHANHOGUEROPU'Ã & \\
NHANDERORY'I & \\
NHANDERORY'I & \\
\hline
\end{tabular}

\begin{tabular}{|l|l|}
\hline NHAMANDU TENONDE (faixa 19) & Nhamandu Pai Primeiro \\
\hline & \\
NHAMANDU TENONDE & Nhamandu Nosso Pai Primeiro \\
OYVARAPY PY & Em sua Morada Celeste \\
IMBA'EKUAA GUI & Com sua Sabedoria \\
ONHEMBOJERA & Desdobrou-se a si mesmo \\
PYTUYMA MBYTE GUI & Na noite original \\
NHANDERU & Nosso Pai \\
NHAMANDU TENONDE & Nhamandu Pai Primeiro \\
\hline
\end{tabular}




\begin{tabular}{|l|l|}
\hline NHAMANDU TENONDE & Nhamandu Pai Primeiro \\
TENONDE & Primeiro \\
TENONDE & Primeiro \\
\hline
\end{tabular}

No CD4, o tema em discussão aparece nas duas faixas seguintes:

\begin{tabular}{|c|c|}
\hline NHANDERU NHAMANDU (faixa 5) & Nosso Deus Sol \\
\hline 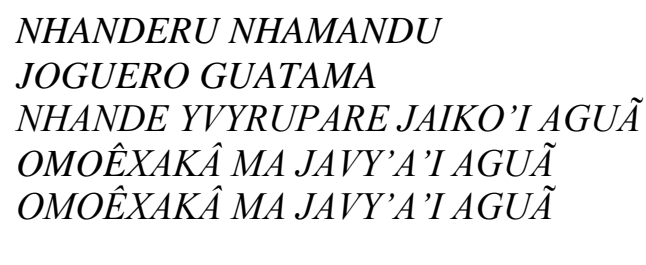 & $\begin{array}{l}\text { Nosso Deus Sol } \\
\text { está se dirigindo } \\
\text { Para o nosso mundo para nos fazer } \\
\text { viver } \\
\text { Iluminando assim nossa alegria } \\
\text { Iluminando assim nossa alegria }\end{array}$ \\
\hline
\end{tabular}

\begin{tabular}{|l|l|}
\hline NHAMANDU OUA RE (faixa 16) & Onde nasce o sol sagrado \\
\hline $\begin{array}{l}\text { NHAMANDU OUA RE JAJEROJY'I } \\
\text { JAUPI NHANDEPO YVATE }\end{array}$ & $\begin{array}{l}\text { Onde nasce o Sol Sagrado, } \\
\text { reverenciamos } \\
\text { NHAROPORANDU NHANDERETE'I } \\
\text { Pevantamos nossas mãos para o alto } \\
\text { Pedindos fortalecer nossos corpos }\end{array}$ \\
\hline
\end{tabular}

Os mborai selecionados compreendem mitopoemas que destacam Nhamandu em seu aspecto sagrado e primordial. Criam-se temáticas convincentes da sua atuação, reveladora de sua divindade solar e expressiva de uma sabedoria (arandu): o raio solar eterno "nasce brilhando", "brilha enquanto se eleva", "irradia alegria e felicidade", "nos levanta" (nhanemopu'â), "nos faz sorrir" (nhanembory), "nos alegra" (nhanembovy'a). O mborai número 19 , do CD2, contém a representação da entidade suprema Nhamandu Tenonde, Nhamandu Pai Primeiro, e sua expressão nhembogera (desdobrou-se em si mesmo).

O mborai número 16 , do CD4, registra um notável grau de reverência às divindades: "levantamos nossas mãos para o alto (jaupi nhandepo yvate), pedindo nos fortalecer (nharoporandu nhanderete')). Percebe-se, nessa linguagem, a realidade do corpo (rete) e sua dinâmica de purificação mediante o verbo pedir (porandu).

A dinâmica ontológica, imanente aos sujeitos, supõe a divindade como representação da sabedoria-alma e se torna expressiva pelo termo py'a rendy, que significa "entendimento através do coração", uma consciência-ânimo de natureza perceptível. O milagre divino caracterizase como guero-yvara, que simboliza a incorporação dos indivíduos à própria divindade, fazendo com que se transformem em parte dela 
mesma (CADOGAN, 1959, p. 26). A expressão guero-moñemoña alude à forma de criação engendrada como parte do próprio ser (CADOGAN, 1959, p. 27).

Os narradores reportam-se à voz da ancestralidade, manifestada pela expressão "Nosso Pai Nhanderu". O movimento autogerado, de si para si, atualiza a transformação do caos em cosmo, da noite em reflexo da sabedoria divina - a luz solar. O espaço existencial é concebido como uma cópia ou sombra, um lugar-tempo onde se vive a realidade. Essas representações partem do imaginário social instituído, segundo o qual o fundamento da vida corpórea é sofrimento e busca incessante para superar a condição de imperfeição e a (re)integração à ordem divina (CASTORIADIS, 1982 apud BORGES, 1998). As mesmas representações também revelam que a fundação de si mesmo, sendo de origem e sentido divinos, constrói a forma-sujeito Mbya. Para o imaginário Guarani, a palavra (o logos divino) é a condição de existência do universo e da vida. Trata-se da vida cosmológica em sua dimensão fundadora do mundo, dos homens e de seu destino divino (BORGES, 1998, p. 209).

A compreensão teogônica dos Mbya considera que Nhamandu Ru Ete, igualmente chamado de Nhande Ru Papa Tenonde ("nosso pai último", "último primeiro"), é o deus fundador, responsável pela origem do mundo - um deus gerador e de si mesmo gerado, que será também o destruidor da terra. Do nome Nhamandu derivam-se outros, tais como Nhamandu'i, Nhamandu Ru Ete, Nhamandu Ru Ete Tenonde e Nhamandu Yma. Um segundo grupo de nomes deriva de Nhande Ru: Nhande Ru Tenonde, Nhande Ru Papa Tenonde, Nhanderu Nhamandu. Nota-se, ainda, o desdobramento de Nhamandu em Nhamandu Ru/Xy Ete (Nhamandu Pai/Mãe verdadeiros), designando os pais e mães verdadeiros da humanidade (CADOGAN, 1959; GODOY, 2003). Pode-se entender que os outros deuses seriam criações de Nhamandu Ru/Xy Ete: Karai Ru/Xy Ete (Karai Pai/Mãe verdadeiro/a); Tupã Ru/Xy Ete (Tupã Pai/Mãe verdadeiros) e Jakaira Ru/Xy Ete (Jakaira Pai/Mãe verdadeiros). (BORGES, 1998, p. 27).

Essas divindades não são concebidas como manifestações de Nhamandu, que é um deus uno, absoluto em sua unicidade, mas sim como entidades dotadas de atributos e domínios próprios (SCHADEN, 1969, p. 123). Com base no modelo-representação, criam-se orientações 
específicas, que têm ascendência sobre o envio das almas/palavras: os nomes (ery), como ocorre no ritual do batismo e na demanda de atuações xamânicas dos chefes religiosos (designados como xeramoī, nossos pais e avós) ${ }^{8}$.

\section{Tupã Ojepovera (“Tupã relampeja, ilumina”)}

No universo cósmico Guarani, Tupã é uma divindade expressiva do mar, do domínio aquático (CADOGAN, 1959, p. 208). "Tupã veio para ser guardião do mundo. Seu brilho (overa) e seu barulho (opororo) são suas armas destruidoras" (LADEIRA, 1992, p. 103). Afirma-se que Tupã foi criado por último (NIMUENDAJU, 1987). Quanto à sua aparência física, vários informantes caracterizam-no como de baixa estatura, com cabelos crespos e usando o tukumbo ("chicote") e o tembekua ("adorno de osso"), mas não o petỹgua ("cachimbo"). Ele é frequentemente mencionado quando há raios e trovões. Durante as rezas, a área posterior da Casa de Reza (opy) é considerada de influência de Tupã - por isso as reverências a essa divindade ocorrem dirigindo-se a esse local o olhar, os gestos e, às vezes, os corpos.

O equilíbrio da terra está ligado à movimentação de Tupã, que ocorre de forma oposta ao sol (Kuaray), do Oeste para o Leste. Observase que essa divindade se estende para outras culturas Tupi e é vista como controladora da morte e da destruição, acarretando, assim, mais medo do que veneração (LARAIA, 1986, p. 103). Por outro lado, o sentido de refrescamento, a suavização do calor, o controle das emoções e o refrescar do coração também se originam de Tupã (BORGES, 1998, p. 272). Examinemos essas observações nas narrativas Guarani.

No CD2, destaca-se a faixa 18 do segundo exemplar:

\begin{tabular}{|l|l|}
\hline NHANDERU TUPÃ (faixa 18) & Nosso Pai Tupã \\
\hline NHANDERU TUPÃ & Nosso Pai Tupã \\
OPOPYGUA OJEPOVERA & Com seu bastão iluminado \\
\hline
\end{tabular}

\footnotetext{
${ }^{8}$ A escrita dos mborai aqui utilizada segue as normas empregadas nas escolas indígenas, em grande parte fundamentadas em R. A. Dooley (Vocabulário do Guarani). Usou-se como base a escrita indígena registrada nos encartes dos CDs. As dúvidas remanescentes foram resolvidas por uma reflexão conjunta entre as autoras e o professor de língua Guarani Jordi Ferri.
} 


\begin{tabular}{|l|l|}
\hline YY GUAXU ROVAIRE & Do outro lado do oceano \\
XONDARO'I & Pequenos guardiões \\
XONDARIA'I & Pequenas guardiãs \\
NHANEPU' A $K A T U$ & Vamos nos erguer \\
JAJEROJY & Reverenciar \\
JAPORAI & Cantar \\
NHANDERU ETE & O nosso Pai Supremo \\
NHANDEXY ETE & A nossa Mãe Suprema \\
NHAMBOVY'A & Alegrar \\
\hline
\end{tabular}

Segue a faixa 12 do CD4:

\begin{tabular}{|l|l|}
\hline TUPÃ (faixa 12) & Tupã \\
\hline & \\
TUPÃ XONDARO'I TUPÃ XONDARIA'I & Guardiões de Tupã, guardiãs de Tupã \\
PEJU KATU PEMOEXAKÃ OREROPY'I RE & Venham iluminar nossa Casa de Reza \\
PEJU KATU PEJEPOVERA OREROPY'I RE & Venham clarear nossa Casa de Reza \\
PEEXAUKA PENDEPOPYGUA & Revelem seus Popygua sagrados \\
\hline
\end{tabular}

\section{Tupã Ra'y (Filho de Tupã, Jesus Cristo): “aqui esperamos o filho de Tupã”}

Tupã Ra'y, filho de Tupã, é a entidade representativa de Jesus Cristo, o filho de Deus, um registro claro de que os subgrupos Guaranis introduziram elementos cristãos em sua tradição mitológica. Essa atribuição deriva-se da importância do fato de Tupã ter enviado seu filho à terra a fim de prestar ajuda ao homem (SCHADEN, 1969, p. 110-111). As analogias entre Tupã e o Deus cristão resultaram do processo de aculturação e de conversão imposto aos povos indígenas americanos entre os séculos XVI e XVIII por missionários jesuítas como uma empresa consciente de aculturação provocada, dirigida e controlada (SCHADEN, 1969).

CD2, faixa 13:

\begin{tabular}{|c|c|}
\hline$T U P \tilde{A} R A^{\prime} Y$ (faixa 13) & O filho de Tupã \\
\hline$T U P \tilde{A} R A^{\prime} Y$ & O filho de Tupã \\
\hline OGUEJY MAVY OGUERU & Quando desce à Terra \\
\hline KARENA MARÃ E' $\tilde{Y}$ & Traz consigo \\
\hline KARENA MARÃ $E^{\prime} \tilde{Y}$ & O trono eterno \\
\hline 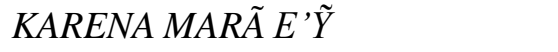 & Traz consigo \\
\hline & $\mathrm{O}$ trono eterno \\
\hline NEE KATU XEREINDY KUE'IRY & \\
\hline NHAMONHENDU MBORAI & Venham, minhas irmãs \\
\hline
\end{tabular}




\begin{tabular}{|l|l|}
\hline NHANDERU TUPÃ AMBA & Vamos todos cantar \\
\hline
\end{tabular}

Observa-se como se impõem as palavras do mborai seguinte:

\begin{tabular}{|l|l|}
\hline NHANDERU RA'Y (faixa 5) & Filho de Deus \\
\hline NHANDERU RA'Y KURUXU MBYTE RE & O Filho de Deus no centro da cruz \\
OJEEXAUKA OJEEXAUKA, & se revelou, se revelou. \\
NHANDERU RA'Y KURUXU MBYTE RE & O Filho de Deus no centro da cruz \\
OJEEXAUKA OJEEXAUKA, & se revelou, se revelou \\
RIRE JEPE OUPITY JEVY NGUU ETE AMBA, & Depois alcançou novamente a \\
RIRE JEPE OUPITY JEVY NGUU ETE AMBA, & Morada do seu Pai Verdadeiro \\
A $\tilde{Y}$ REVE OJEPOVERA OJEPOVERA, & Depois alcançou novamente a \\
AY REVE OJEPOVERA OJEPOVERA & Morada do seu Pai Verdadeiro \\
& Até hoje brilhando, brilhando. \\
& Até hoje brilhando, brilhando. \\
\hline
\end{tabular}

As narrativas expressam o sentido cristão nelas materializado. Não se trata de uma influência simples, e sim de uma forma de recriação mítica efetuada pelos índios, que usam diversas expressões extraídas do ideário cristão para se referir a Tupã Ra'y: "aqui esperamos", "revelou-se e alcançou novamente a morada do seu pai verdadeiro", "revelou-se no centro da cruz" (SCHADEN, 1982, p. 12; 1989), denotando um processo de releitura do mito original à luz de informações trazidas por missionários. É preciso entender que a capacidade de gerar imagens de esperança e parábolas contextualizadas de vida, força original do cristianismo, são expressivas do fenômeno religioso Guarani e "viven algo proprio, inspirado y divino" (MELIÀ, 1997, p. 135).

\section{Profetismo e religiosidade na consagração dos mborai}

Os mitopoemas e a palavra "mito" assumem significados relativos a tempo-espaço-renascimento, introduzindo o sentido real com que a memória é vivenciada e postulando um sentido de veracidade. São formas verbais que funcionam como testemunhos míticos. Os sujeitos verbais, convencidos (mbojerovia: "fazer crer") de seus desejos de imortalidade, de ultrapassar o plano material, de ir para Yvy Mara É̃y, têm sua origem na negação do tempo profano, que é uma sombra do tempo verdadeiro. Por meio da atuação conjunta, ordena-se um tempo de renovação "aquele que, ao se repetir, transforma, retorna e avança, diferencia-se, 
faz-se outro: um tempo que se faz passagem, retorno e ultrapassagem" (BORGES, 2002, p. 119). Na teogonia Mbya, arandu porã (o "belo saber") identifica os compromissos dos sujeitos como uma expressão mística divina, individual e, ao mesmo tempo, coletiva, num universo simbólico onde "é possível negar a condição humana, de modo-radical, e tornar-se divino sem passar pela prova da morte" (VIVEIROS DE CASTRO, 1984-5, p. 19).

A identidade cultural, implícita na dimensão de oralidade tradicional, segue um rumo que desloca o sentido ancestral das caminhadas - a busca da salvação no lugar do sagrado -, comprometendo-se com a dinâmica do messianismo (SCHADEN, 1982; CLASTRES, H, 1978; MELIÀ, 1990; BRANDÃO, 1990, p. 74-75). A crise se instala diante do fato de que não é mais possível aos humanos seguir essa viagem (oguataa: "caminhada") em função do adiamento do cataclismo, que uma vez já aniquilou o universo, a "primeira terra" (SCHADEN, 1982; BRANDÃO, 1990, p. 77). As alusões a Yvy Mara Ẽ̃y enquanto uma busca mais ecológica do que religiosa - isto é, de territórios virgens para a caça e a prática da agricultura indígena (MELIÀ, 1990) - podem ser estendidas para a estrutura comemorativa e emancipatória das narrativas quando expressam significados míticos. Dessa perspectiva, observamos que alguns mitopoemas se expressam "como uma resposta ao mal, que é o valor do branco e tudo o que ele conduz [...] ou como a vocação coletiva da história transformada em um desejo de ética" (BRANDÃO, 1990, p. 72). As experiências reiteram que a religião dos antigos e o sistema de crenças devem ser preservados. Assim, a adoção de elementos do cristianismo reforça a estratégia para melhor conservar as crenças e os valores tradicionais, "concedendo para não ceder" (SCHADEN, 1982, p. 2). A formulação teológica doutrinária dos Mbya inclui elementos do cristianismo, tais como o batismo e o uso da cruz ou do crucifixo. Também o sistema musical simboliza a presença de traços ocidentais (SETTI, 1988).

É preciso notar, não obstante, que a resistência nativa e a incorporação dos elementos do cristianismo projetam-se como formas criativas no "núcleo duro", especificamente Guarani (BORGES, 2001, p. 14). Nesse núcleo, habitar a alma sagrada por meio da palavra rememorada dos deuses, dos verdadeiros Pais e Mães, torna-se metáfora 
das expressões mborayvu (concepção ligada ao sentido compartilhado da palavra, traduzido por "amor") e aguyje (que designa aperfeiçoamento e implica o cumprimento rigoroso da lei segundo o Criador, espelhando-se nele como uma imagem dos "enfeitados", "escolhidos"). As manifestações da palavra do canto e do movimento da dança são enfatizadas como uma devoção dos Mbya às práticas religiosas autóctones (MELIÀ, 1997, p. 127).

A linguagem poética dos mborai é a que se pode observar cotidianamente na Casa de Rezas (opy), quando são invocados os conhecimentos sagrados como recursos míticos criativos. Assim, ouvimos as seguintes exclamações discursivas, que reforçam a linguagem poética descrita:

- Japorairã nhanhembo'e'i: "enquanto cantamos, aprendemos conteúdos sagrados";

- Japyta nhande py'are: "ficamos (dominados) em nossos corações";

- Petỹgua jajopy reko axy'i: "fumamos nesta era das imperfeições";

- Tataxina reko axy'i: "fumaça sagrada da era das imperfeições";

- Nharoporandu nhanderete'i, nhanderu pe: "cantamos pelos nossos corpos, invocando a Deus";

- Ayvu anhentegua: "as verdadeiras palavras", que vêm dos espíritos (envolvem um estado de meditação).

Lembra-se do clima profético desta contextualização sob a neblina vivificante: tatachina reko axy, emanada da fumaça do tabaco (petỹ).

\section{Considerações Finais}

Nos últimos dez ou quinze anos, várias aldeias indígenas sofreram intervenções em sua organização tradicional, que ocasionaram modificações de natureza intercultural nos seus espaços de sociabilidade. A dinâmica daí decorrente culminou na formação de novos espaços, mas neles permanece viva a memória registrada nos mitopoemas, saberes cristalizados sobre a mitologia e a sociedade tradicional, que são, em última instância, o núcleo fundamental da cultura Guarani Mbya. 
As narrativas que falam sobre a origem e os destinos dos Guarani foram gravadas em CDs, constituindo uma fonte ampla e segura sobre o imaginário coletivo e a identidade desse povo. Por meio deles, pode-se compreender o passado imemorial dos Guarani, as noções que possuem sobre o seu devir e a cultura tal como a compreendem no contexto de autovalorização das tradições - a marca básica de sua organização social.

Os mborai registram o desejo dos índios de ser como os seus deuses, detendo o poder de anular ou adiar a angústia e o sofrimento do presente, numa reiteração do caráter melancólico e pessimista desde há muito assinalados por diversos autores.

\section{Referências bibliográficas}

BORGES, L. C. Fala Instituinte do Discurso Mítico Guarani Mbya. 1998. 373 f. Tese (Doutorado em Linguística e Estudos da Linguagem) - Campinas, Universidade Estadual de Campinas, [1998].

Oralidade e Autoria em Narrativas Míticas Guarani Mbya. Revista Anpoll, n. 10, p. 179-204, 2001. $122,2002$.

Os Guarani Mbya e a Categoria tempo. Tellus, Campo Grande, v. 2, n. 2, p. 105-

Temporalidade e Memória: estratégias contemporâneas da identidade Guarani. Anais do $54^{\circ}$ International Congress of Americanists. Building dialogues in the Americas. Rio de Janeiro: Nucleas/UERJ, 2012. v. 1. p. 1-20.

BRANDÃO, Carlos Rodrigues. Os Guarani: índios do Sul - Religião, resistência e adaptação. Estudos Avançados, São Paulo, v. 4, n. 10, p. 53-90, 1990.

CADOGAN, León. Ayvu Rapyta: textos míticos de los Mbyá-Guarani del Guaíra. São Paulo: USP/FFLCH, 1959. (Boletim 227, Antropologia 5).

CASTAGNA, Paulo. A música como Instrumento de Catequese no Brasil dos Séculos XVI e XVII. In: MONTEIRO, John Manuel; AZEVEDO, Francisca L. N. (Org.). Confronto de Culturas: conquista, resistência, transformação. Rio de Janeiro: Expressão e Cultura/São Paulo: EDUSP, 1997. p. 275-290.

CHAMORRO, Graciela. A espiritualidade Guarani: uma teologia ameríndia da palavra. São Leopoldo: Sinodal, 1998. 
CLASTRES, Hélene. Terra Sem Mal: o profetismo Tupi-Guarani. São Paulo: Brasiliense, 1978.

CLASTRES, Pierre. A fala sagrada, mitos e cantos sagrados dos índios Guarani. Campinas: Papirus, 1990.

DOLLEY, Robert A. Vocabulário do Guarani. Brasília: Summer Institute of Linguistics, 1982.

GODOY, Marília G. Ghizzi. Os rituais de canto-dança e de formação da palavra-almanome entre os Guarani Mbya. In: CARVALHO, Silvia M.S. (Org.). Rituais Indígenas Brasileiros. São Paulo: CPA Editora, 1999. p. 158-168.

O Misticismo Guarani Mbya na era do sofrimento da imperfeição. São Paulo: Terceira Margem, 2003.

A música e a dança Guarani Mbya como recursos de cidadania e identidade étnica. In: Olhares e diálogos sociológicos sobre as mudanças no Brasil e na América Latina. IV Seminário do PPG em Sociologia da UFSCar, São Carlos, 2013, v. 1, p. 3046.

GODOY, Marília G. Ghizzi; SILVA, Dilma de Melo. Terra Sem Males: Utopia e Realidade, nos discursos dos mborai (cantos) Guarani Mbya. Revista Arte e Cultura da América Latina, Sociedade Científica de Estudos das Artes, São Paulo, v. 31, p. 1530, 2014.

HUIZINGA, John. Homo ludens: o jogo como elemento da cultura. São Paulo: Perspectiva, 1971.

HUIZINGA, Johan. Homo Ludens. Madri: Alianza Editorial, 1972.

IBGE. Censo Demográfico, 1991/2010.

LADEIRA, Maria Inês. O caminhar sob a luz: o território Mbya à beira do oceano. 1992. 199 f. Dissertação (Mestrado em Ciências Sociais) - São Paulo, Pontifícia Universidade Católica, [1992].

LARAIA, Roque de Barros. Tupi: índios do Brasil atual. São Paulo:USP, 1986. (Série Antropologia, n. 11).

Cultura: um conceito antropológico. Rio de Janeiro: Jorge Zahar, 1992.

LITAIFF, Aldo. Os filhos do sol: mitos e práticas dos índios Mbya Guarani do litoral brasileiro. Tellus, Campo Grande, v. 4, n. 6, p. 15-30, 2004.

MELIÀ, Bartomeu. A experiência religiosa guarani. In: MELIÀ, Bartomeu et al. (Org.) O rosto índio de Deus. Rio de Janeiro: Vozes, 1989. p. 293-357. 
A terra sem mal dos Guarani: economia e profecia. Revista de Antropologia, São Paulo, v. 33, p. 33-46, 1990.

En busca de una teologia indígena (a partir de una experiencia Guarani). In: SIDEKUM, A. (Org.). História do Imaginário Religioso Indígena. São Leopoldo: Unisinos, 1997. p. 125-144.

MONTARDO, Deise Lucy Oliveira. Através do mbaraka: música e xamanismo guarani. 2002. 276 f. Tese (Doutorado em Antropologia Social) - São Paulo, Universidade de São Paulo, [2002].

NIMUENDAJU, Curt Unkel. As lendas da criação e destruição do mundo como fundamentos da religião dos Apapocuva-Guarani. São Paulo: Hucitec - EDUSP, 1987.

SCHADEN, Egon. Aculturação indígena: ensaio sobre fatores e tendências de mudança da cultura de tribos índias em contato com o mundo dos brancos. São Paulo: EDUSP, 1969.

Aspectos fundamentais da cultura Guarani. São Paulo: EDUSP, 1974.

A religião Guarani e o cristianismo: contribuição ao estudo de um processo histórico de comunicação intercultural. Revista de Antropologia, São Paulo, v. 25, p. 124, 1982.

SETTI, Kilza. O sistema musical dos índios Guarani de São Paulo. In: Jornal O Estado de São Paulo, 7.12.1988.

STEIN, Marília Raquel Albornoz. Kyringüe Mborai: os cantos das crianças e a cosmosônica Mbya Guarani. 2009. 309 f. Tese (Doutorado em Música) - Porto Alegre, Universidade Federal do Rio Grande do Sul, [2009].

SUESS, Paulo. Reconhecimento e protagonismo: apontamentos em defesa do projeto histórico dos outros. In: SIDEKUM, A. (Org.). História do Imaginário Religioso Indígena. São Leopoldo: Unisinos, 1997. p. 25-35.

TERRIN, A. N. O rito: antropologia e fenomenologia da ritualidade. São Paulo: Paulus, 2004.

VIVEIROS DE CASTRO, Eduardo. Bibliografia etnológica básica tupi-guarani. Revista de Antropologia, São Paulo, v. 27-28, p. 7-24, 1984-85.

ISA/FUNAI. Diário Oficial da União. 2013. Disponível em: www.pib.socioambiental.org/pt/c/quadro-geral. Acesso em: 16 out. 2015.

CD's 
Ñande Reko Arandu - Memória Viva Guarani. Instituto Teko Arandu, 1998.

Ñande Arandu Pygua - Memória Viva Guarani. Instituto Teko Arandu, 2004.

Tape Mirim - Tekoa Itaty (Aldeia Morro dos Cavalos - Santa Catarina). Grupo Mbya Guarani Tape Mirim (não datado).

Guardiões Guarani Kyringue Nhembovy'a - Aldeia do Rio Silveira (2011-2012).

Recebido em: 17/06/2016 * Aprovado em: 21/09/2017 * Publicado em: 31/12/2017 